Australian Journal of

Educational Technology

\title{
Do vendor/consultant services affect small business' IT course requirements?
}

\author{
R. C. MacGregor and D. J. Bunker \\ University of Wollongong \\ R. S. Cocks \\ Wollongong Veterinary Hospital \\ J . K. Pierson and K. A. Forcht \\ James Madison University
}

\begin{abstract}
This paper compares two studies carried out in the area of small business in Australia. The first of these studies examined one branch of the 'scientific' small business community, veterinary practitioners. In particular, the study examined the computer training required by the city-based and countrybased veterinarians. The second study examined the computer training needs of general small business managers in a city-based environment. Not only did both studies attempt to determine specific curricula needs, both examined the effect of vendor/consultant services on those curricular choices. The paper begins by briefly describing the nature of both the veterinary profession and small business in Australia. The paper then presents details of each of the studies. Finally the paper compares the findings of each of the studies, highlighting similarities as well as differences in the small business types.
\end{abstract}

A major concern facing curriculum designers is to provide a balanced course of instruction such that upon completion an individual is employable and useable within an organisation. In the area of Information Systems (IS) Nelson (1991) suggests that the rapid advances of Information Technology (IT) has widened the gap between what an individual knows 
and what they are expected to know to fully exploit IS in their organisation. No more apparent is this than in the area of small business. Indeed, while many studies have examined the needs of larger organisations in the development of an IS curriculum (Lo, 1991; Ang \& Lo, 1991; Ang, 1992; Trauth et al, 1993), few have focused on the needs of their small business counterparts.

While the desire for small business to adopt IT in their day to day running has increased (Neergaard 1992, MacGregor \& Cocks 1994), the skill and knowledge required by most small business managers to plan, implement and maintain that technology has lagged behind (Holzinger \& Hotch 1993). Thus, despite recent findings (Delvecchio 1994) which suggest that there is a genuine desire by small business managers to acquire requisite knowledge of IT, most small businesses have tended to rely on vendors for the necessary background knowledge to purchase and use computers.

A number of factors appear to impinge both on small business management's perception of IT as well as their perception of curricula inclusions. Yap et al (1992) have shown that management's perception of IT is positively associated with consultant expertise and the level of vendor support. Igbaria (1993) found that factors such as organisational size, age, decentralisation, system quality and user involvement would normally form part of such models. However, he suggests that when considering non-computing professionals, and in particular the association with vendors, variables such as staff training, vendor assistance and manuals provide a more valid view of management's perception of IT.

\section{The Australian veterinary profession}

The Australian veterinary profession is subdivided into four distinct groups: small animal, large animal, academic and government. For the purposes of this study, only the small animal and large animal veterinary practices have been considered. Traditionally small animal veterinary practices are city based practices providing services to household pets. Large animal practices are traditionally rural practices concentrating on herd animals. The veterinary profession, like most areas of medical science, has always attempted to remain 'current' both in professional practice and course offerings. Today, a variety of journals not only 
provides the profession with new medical technology, but all facets of practice management. The use of computers within the day to day running of the practice has been one of the topics 'aired' in journals (Waldhalm 1991, MacGregor \& Cocks 1991, 1994). More recently, the profession appears to be examining computing courses both at an undergraduate as well as a postgraduate level.

\section{The nature of small business}

The nature of small business has been the topic of both governmental committee findings as well as research initiatives. Brigham \& Smith ( 1967) found that small businesses tended to be more risky than their larger counterparts. This view is supported by later studies (Walker, 1975; Delone, 1988). Cochran (1981) found that small businesses tended to be subject to higher failure rates while Rotch (1987) suggested that small businesses tended not to maintain adequate records of transactions. Perhaps most important in any discussion concerning small business is the view given by Barnett \& Mackness (1983), that small businesses are not miniature versions of larger businesses, but quite unique in their own right.

Perhaps the most detailed definition of a small business was provided by Reynolds et al (1994). They suggested that the following characteristics make up the organisational environment in which a small business operates:

- small management team

- strong owner influence

- centralised power and control

- lack of specialist staff

- multi-functional management

- a close and loyal work team

- informal and inadequate planning and control systems

- lack of promotable staff

- lack of control over business environment

- limited ability to obtain finance

- labour intensive work 
- limited process and product technology

- narrow product/service range

- limited market share

- heavy reliance on few customers

- decisions - intuitive instead of rational

- leadership - personal but not task oriented

- education experience and skill - practical but narrow

- low employee turnover

- product dedication rather than customer orientation

- reluctance to take risks

- management swayed by personal idiosyncrasies

- strong desire to be independent

- intrusion of family interests

When the introduction of IT into small business is considered, there are marked differences between small businesses and their larger counterparts (Barnett \& Mackness 1983). Khan \& Khan (1992) suggest that most small businesses avoid sophisticated software or applications. This view is supported by studies carried out in the United Kingdom by Chen (1993). Cragg \& King (1993) suggest that small businesses often lack the necessary expertise to fully utilise IT. This view is supported by the findings of Holzinger \& Hotch (1993) and Delvecchio (1994). Indeed, Yap et al (1992) have shown that many small businesses use consultant or vendor expertise in the identification of hardware and software as their first critical step towards computerisation. They conclude that ongoing success with IT is positively associated with vendor support, vendor training, vendor after sales service and vendor expertise. This is supported in recent studies (MacGregor \& Cocks 1994, Wood \& Noiek 1994, MacGregor \& Bunker 1995).

Added to the views and findings concerning small business, are the variety of definitions of what actually constitutes a small business. Some definitions tend to be based purely on a quantitative perspective, either amount of staff, or amount of turnover, while others attempt to utilise a qualitative definition, similar to those provided by Savage et al (1994). 
Meredith (1994) suggests that any definition of a small business must include a qualitative as well as a quantitative component. The quantitative component should examine staff, turnover, assets as well as any other financial measure, while the qualitative component should reflect mode of operation as well as organisational procedures.

Not only are there a myriad of views concerning the nature of small business, but from a governmental standpoint there are a variety of definitions of small business. In the United Kingdom a small business is defined as:

having fewer than 50 employees and was not a subsidiary to any other company.

In the United States:

a small business concern shall be deemed to be one which is independently owned and operated and which is not dominant in its field of operation (United States Small Business Administration - based on section 3 of the Small Business Act 1953).

While in Australia, a small business is defined as:

small business is one in which one or two persons are required to make all the critical decisions (such as finance, accounting personnel, inventory, production, servicing, marketing and selling decisions) without the aid of internal (employed) specialists and with the owners having knowledge in one or two functional areas of management. (Meredith 1994, p 31 ).

The definition of small business is further 'clouded' when current research is considered. Many researchers not only ignore governmental guidelines concerning the nature of small business, but tend to apply their own criteria, further narrowing political parameters. Recent studies, however. (Delone 1988, Chen 1993), have attempted to utilise governmental guidelines, by utilising mailing lists prepared by governmental agencies. Thus decisions concerning the nature and definition of small businesses becomes the responsibility of such agencies, rather than the researcher. This current study has adopted a similar approach.

\section{Computer curriculum requirements}

Based on ACM and DPMA curriculum models, Lo (1991) suggested that in order to fully examine all possible curriculum inclusions, decisions needed 
to be made across 51 subtopics. These subtopics have been utilised in a number of studies both in Australia and South East Asia (Ang \& Lo, 1991; Ang, 1992). Seeborg \& Ma (1989) suggested that when non-computing groups were considered, the number of subtopics should be considerably reduced. As such, Lo's original 51 subtopics has been reduced to 15 (see Table 1).

Table 1. Curriculum subtopic

\begin{tabular}{|l|l|}
\hline \multicolumn{1}{|c|}{ Subtopics } & \multicolumn{1}{c|}{ Brief Description } \\
\hline $\begin{array}{l}\text { Structure and function of } \\
\text { computer hardware }\end{array}$ & study of the major components of the microcomputer \\
\hline Programming & problem solving and program development \\
\hline Database/Spreadsheets & $\begin{array}{l}\text { the use of databases and spreadsheets in common } \\
\text { business problems }\end{array}$ \\
\hline Business Analysis & analysis of the major functions and data in the business \\
\hline Information Analysis & data modelling techniques \\
\hline Office Automation & integration of the microcomputer into the office \\
\hline $\begin{array}{l}\text { Business Accounting } \\
\text { Systems }\end{array}$ & design and use of accounting software \\
\hline $\begin{array}{l}\text { Computer Evaluation } \\
\text { Techniques }\end{array}$ & $\begin{array}{l}\text { techniques for testing and comparing potential } \\
\text { hardware and software purchase options }\end{array}$ \\
\hline Accountancy & introductory principles of accounting \\
\hline Finance & $\begin{array}{l}\text { introduction to corporate valuations and financial } \\
\text { markets }\end{array}$ \\
\hline Marketing & market segments, buyer behaviour, etc. \\
\hline Business Law & partnerships, liabilities, contracts, etc. \\
\hline Statistics & descriptive and inferential statistics \\
\hline Management Principles & goal determination implementation, etc. \\
\hline Interpersonal Skills & verbal, written, formal and informal communication \\
\hline & \\
\hline
\end{tabular}

\section{Survey instrument}

A questionnaire was developed for both of the studies. With the exception of terms such as 'type of practice' and 'type of small business' the questions were identical. The questionnaire sought information concerning satisfaction with vendor/consultant services, in particular those factors suggested by Igbaria (1993): 
- adequacy of vendor training

- adequacy of vendor manuals

- adequacy of vendor after sales assistance

In each case respondents were asked to rate the criteria as satisfactory or unsatisfactory. The questionnaire also required respondents to rate each of the subtopics ( 1 not important - 5 very important) in terms of perceived importance in training tor a newly hired member of staff.

For the study involving the veterinary practitioners, the questionnaires were distributed throughout Australia through the Australian Post Graduate Veterinary Foundation as an inclusion in their regular information package.

For the study involving general small business, a mailing list was developed by a government agency. The mailing list was developed by the Illawarra Chamber of Commerce and is known as the Illawarra Business Directory. The geographic area covered by this directory includes the southern suburbs of Sydney, Wollongong and Nowra (population approximately 500,000). The sampling frame developed from this directory was small companies who had a work force of 50 or less, where the company was not a subsidiary of a larger company. Computing companies were excluded from the survey.

Small businesses were categorised into one of four types, these categories being gleaned from the directory:

Finance includes investment and tax consultants, accounting firms and insurance brokers

Industrial includes manufacturing, building and construction industries

Customer Service retail, transport, tourism, media

Professional architects, medical, surveyors, legal 


\section{Analysis of results}

Veterinary study

3090 Questionnaires were distributed. Responses were gained from 219 veterinary practices. While the response rate $(7.1 \%)$ was below the normally anticipated $10 \%-30 \%$ response rate for questionnaire sampling, it was felt that the size of the return sample warranted examination.

Furthermore, it was considered that since the questionnaire was part of a large information package, this may have lowered the return sample size. Table 2 provides the demographics of the return sample.

Table 2. Demographics of the veterinary return sample (Practices using IT $=166$; practices not using IT $=53$ )

\section{Practices without} a computer

1 person
2 person
3 person
4 person
5 person
$5+$ person

\section{Practices with a computer}

\section{General small business study}

A total of 600 questionnaires were distributed. Responses were obtained from 131 businesses, representing a response rate of $21.8 \%$. All respondents indicated that they were using IT in their day-to-day work. Table 3 indicates the responses subdivided into business type.

Table 3. Demographics of the general small business return sample

Industrial

Professional

Customer Services 
Table 4 provides an overall summary of responses concerning the perception of vendor services.

Table 4. Small business managers' perception of vendor/consultant services

\begin{tabular}{|c|c|c|c|c|}
\hline \multirow[t]{2}{*}{ Service } & \multicolumn{2}{|c|}{$\begin{array}{l}\text { Veterinary } \\
\text { respondents }\end{array}$} & \multicolumn{2}{|c|}{$\begin{array}{l}\text { Small business } \\
\text { Respondents }\end{array}$} \\
\hline & Satisfied & $\begin{array}{c}\text { Not } \\
\text { satisfied }\end{array}$ & Satisfied & $\begin{array}{l}\text { Not } \\
\text { satisfied }\end{array}$ \\
\hline $\begin{array}{l}\text { Training } \\
\text { After Sales Service }\end{array}$ & 106 & 101 & 81 & 54 \\
\hline Manuals / & 117 & 90 & 99 & 36 \\
\hline Documentation & 108 & 99 & 87 & 48 \\
\hline
\end{tabular}

\section{The importance of IT courses at undergraduate level}

The responses were examined to determine the overall opinion of respondents concerning the importance of IS courses at an undergraduate level. Responses were grouped into 3 categories:

\section{Category}

Those who thought that some form of IS training was very important Those who thought that some form of IS training was quite important Those who did not think that IS training was important

\section{Criteria}

At least one of the subtopics rated as 5 - very important

At least one of the subtopics rated as 4 - quite important

No subtopic rated above 3 - little importance

Table 5 indicates overall responses.

Table 5. Overall responses on the importance of IT courses at undergraduate level

\section{Rate}

Very

Important

Important

Not Important

\section{Veterinary practitioners}

174

30

15

\section{General small business} managers

99

12 
Table 6 is a summary of responses by veterinary practitioners and small business managers showing the importance of each of the subtopics.

Table 6. Relative Importance of each of the subtopics

\section{Topic}

Structure/function of hardware

Programming

Database / Spreadsheet

Business Analysis

Information Analysis

Office Automation

Business/ Accounting Systems

Evaluation Techniques

Accounting

Finance

Marketing

Business Law

Statistics

Management Principles

Interpersonal Skills

\section{Veterinary practitioners}

mean rank mean rank

$\begin{array}{cccc}1.96 & 13 & 3.16 & 10 \\ 1.84 & 14 & 3.09 & 13 \\ 2.74 & 1 & 4.18 & 2 \\ 2.66 & 4 & 4.04 & 4 \\ 2.69 & 3 & 4.08 & 3 \\ 2.31 & 8 & 3.75 & 6 \\ 2.70 & 2 & 4.28 & 1 \\ 2.19 & 11 & 3.39 & 8 \\ 2.48 & 7 & 4.01 & 5 \\ 2.25 & 9 & 3.65 & 7 \\ 2.49 & 6 & 3.10 & 12 \\ 1.69 & 15 & 2.65 & 15 \\ 2.00 & 12 & 2.99 & 14 \\ 2.51 & 5 & 3.16 & 10 \\ 2.24 & 9 & 3.19 & 9\end{array}$

An examination of introductory computing courses offered to professionals suggests that they normally offer no more than 6 subtopics (MacGregor \& Cocks 1994). It is instructive to examine which six subtopics are required by each of the small business groups (see Table 7). 
Table 7. Six most requested course inclusions

\section{Topic}

Structure/function of hardware

Programming

Database/ Spreadsheet

Business Analysis

Information Analysis

Office Automation

Business/ Accounting Systems

Evaluation Techniques

Accounting

Finance

Marketing

Business Law

Statistics

Management Principles

Interpersonal Skills

Table 8. Subtopics affected by the satisfaction/dissatisfaction with vendor provided training

\section{Veterinary study}

\begin{tabular}{lcccccc}
\hline Subtopic & & 1 & 2 & 3 & 4 & 5 \\
Finance & Satisfied & 11 & 12 & 32 & 14 & 24 \\
& Dissatisfied & 10 & 14 & 27 & 33 & $17^{* *}$
\end{tabular}

\section{General small business study}

\begin{tabular}{lcccccc}
\hline Subtopic & & 1 & 2 & 3 & 4 & 5 \\
Marketing & Satisfied & 9 & 6 & 20 & 22 & 5 \\
& Dissatisfied & 3 & 6 & 19 & 10 & $16^{* *}$
\end{tabular}

${ }^{* *}$ significant $(\mathrm{p}<0.05)$

\section{Veterinary General small practitioners business}


The data were examined, using a chi-square analysis, to determine if satisfaction/dissatisfaction with vendor training affected the rating of subtopics. Table 8 shows those subtopics affected by the level of satisfaction with vendor training.

Similarly, the data was examined using a chi-square analysis, to determine if satisfaction/dissatisfaction with vendor supplied manuals and documentation affected the rating of subtopics. Table 9 shows those subtopics affected by the level of satisfaction with vendor provided manuals and documentation.

Table 9. Subtopics affected by the satisfaction/dissatisfaction with vendor provided manuals and documentation

\begin{tabular}{lclllll}
\hline Veterinary study & & & & & & \\
\hline Subtopic & & 1 & 2 & 3 & 4 & 5 \\
Evaluation Techniques & Satisfied & 8 & 20 & 39 & 14 & 27 \\
& Dissatisfied & 12 & 8 & 24 & 20 & $35^{*}$ \\
Marketing & Satisfied & 10 & 12 & 33 & 23 & 33 \\
& Dissatisfied & 7 & 15 & 11 & 29 & $27^{* *}$ \\
\hline General small business study & & & & & & \\
\hline Subtopic & & 1 & 2 & 3 & 4 & 5 \\
Statistics & Satisfied & 5 & 13 & 17 & 24 & 28 \\
& Dissatisfied & 6 & 6 & 20 & 7 & $9^{* *}$ \\
\hline
\end{tabular}

${ }^{*}$ significant $(\mathrm{p}<0.1) ;{ }^{* *}$ significant $(\mathrm{p}<0.05)$

The final parameter suggested by Igbaria was termed vendor after sales assistance. A chi-square analysis was applied to the data from both studies to determine if satisfaction/dissatisfaction with vendor after sales service affected the rating of any of the subtopics. Table 10 provides those subtopics affected by satisfaction/dissatisfaction with vendor after sales assistance. 
Table 10. Subtopics affected by satisfaction/dissatisfaction with vendor after sales assistance

\begin{tabular}{lclllll}
\hline Veterinary study & & & & & & \\
\hline Subtopic & & 1 & 2 & 3 & 4 & 5 \\
Programming & Satisfied & 35 & 23 & 19 & 21 & 19 \\
& Dissatisfied & 20 & 15 & 22 & 4 & $11^{* *}$ \\
Accounting & Satisfied & 9 & 16 & 35 & 25 & 33 \\
& Dissatisfied & 5 & 11 & 10 & 27 & $18^{* *}$ \\
Interpersonal Skills & Satisfied & 18 & 13 & 27 & 23 & 35 \\
& Dissatisfied & 6 & 19 & 11 & 12 & 20 \\
\hline General small business study & & & & & & \\
\hline Subtopic & & 1 & 2 & 3 & 4 & 5 \\
Structure/Function of Hardware & Satisfied & 8 & 3 & 21 & 27 & 19 \\
& Dissatisfied & 2 & 6 & 12 & 6 & $11^{* *}$ \\
Statistics & Satisfied & 5 & 11 & 21 & 27 & 14 \\
& Dissatisfied & 6 & 8 & 16 & 4 & $3^{* *}$ \\
Interpersonal Skills & Satisfied & 4 & 12 & 17 & 24 & 21 \\
& Dissatisfied & 5 & 1 & 13 & 12 & $6^{*}$ \\
\hline$*$ significant $(\mathrm{p}<0.1) * * *$
\end{tabular}

${ }^{\text {* }}$ significant $(\mathrm{p}<0.1) ;{ }^{* *}$ significant $(\mathrm{p}<0.05)$

\section{Discussion}

An examination of table 4 would suggest that there is substantial dissatisfaction with consultant/vendor services, both with veterinary practitioners and small business, in general. $48.7 \%$ of veterinary practitioners indicated that they were not satisfied with vendor/ consultant provided training. This figure reduced to $41.2 \%$ for the general small business community. Similar figures were found for vendor/consultant after sales service $(43.4 \%$ vs $27.4 \%)$, as well as vendor/consultant supplied manuals and documentation $(47.8 \%$ vs $36.6 \%)$. 
If the overall responses are considered (see Table 5), the results from both studies suggest that there is a perception by small business managers of the importance of some form of IT training at the college level. This appears to be consistent with the findings of Ang (1991, 1992). Not only does there appear to be a positive response towards computer courses' but any examination of Tables 6 and 7 would suggest that there is a high degree of consensus about the subtopics which should be included in such a course.

Table 8 indicates those subtopics affected by the level of satisfaction in terms of vendor supplied training. A number of issues are apparent. Firstly, as already noted, almost $50 \%$ of respondents in both studies indicated that they were dissatisfied with the training provided by the vendor. In both studies it is only those subtopics which do not fall into the group deemed most desirable that are affected by the level of satisfaction with vendor training. An examination of responses would suggest that those respondents who were dissatisfied with vendor provided training rated subtopics higher than those respondents who were satisfied.

Table 9 shows those subtopics affected by the level of satisfaction in terms of vendor provided documentation and manuals. As already mentioned, there is a high degree of dissatisfaction by small business managers as regards the appropriateness of manuals and documentation. Unlike the effects of satisfaction/dissatisfaction with vendor/consultant supplied training, it would appear, at least with the veterinary respondents that the level of satisfaction/dissatisfaction with manuals does affect some subjects which are deemed essential by the respondents. Of particular interest is the effect of the level of satisfaction with vendor provided documentation and manuals on the respective respondent groups. In the general small business community, those who were satisfied with vendor produced documentation and manuals rated the subtopics higher than those who were dissatisfied. This trend is reversed in the veterinary responses. 35\% of the veterinary respondents who were satisfied with vendor documentation and manuals rated the subtopic Evaluation Techniques as important or very important. By comparison, 53\% of those who were dissatisfied rated the subtopic the same way. Similar figures can be seen for the subtopic Marketing ( $47 \%$ vs. 63\%). In the general small business group, $59 \%$ of those who expressed satisfaction with vendor supplied 
documentation and manuals rated the subtopic Statistics as important or very important. By comparison, only 33\% of those who were dissatisfied rated the subtopic in the same manner.

Table 10 provides those subtopics which were affected by the level of satisfaction with vendor after sales service. With the exception of the subtopic Accounting, all subtopics affected by the level of satisfaction with after sales service did not appear in the group deemed most required and in all cases those who were satisfied with after sales service rated the subtopic higher than those who were dissatisfied. By comparison, the subtopic Accounting received a higher rating by those who were dissatisfied with vendor after sales service than those who were satisfied with it.

\section{Conclusion}

This paper has compared two independent studies which focused on the effect of vendor/consultant service on curricular inclusions for IT courses directed towards small business managers. Both studies used a number of factors previously shown to affect the user's perception of satisfaction with computer technology. These were applied to a widely accepted group of subtopic inclusions to determine the effect of these factors on subtopic ratings. The results of both studies show experience associated with vendor groups can significantly affect the rating of certain subtopics. They further show that these effects are not standard across the small business community, but rather, are dependent upon the type of work being undertaken by the small business.

A number of studies (Yap et al 1992, Holzinger \& Hotch 1993, Delvecchio 1994) have shown that many small businesses seek external help when dealing with IT. These studies have concluded that very often the external help agent fails to understand the business, resulting in the lowering of satisfaction with the newly acquired computer technology. The two studies, presented in this paper show that not only is there dissatisfaction with external vendor groups, but that this dissatisfaction significantly affects perceptions of curriculum design and curricula inclusions.

Of particular interest are the type of subtopics which appear to be affected by the various measures of satisfaction. Broadly, it would appear that dissatisfaction tends to affect those subtopics not within the group deemed 
most required. However, it seems that the level of satisfaction with vendor provided documentation and manuals does affect subtopics within the 'essential' group.

Perhaps most importantly, this study has raised a number of important issues which need to be addressed both by vendor organisations as well as small business managers (scientific as well as general small business). It is apparent from this current study that there is a real need for the small business manager to communicate support requirements expected within the organisation.

For the vendor organisations the results suggest that for the most part training, assistance and documentation are less than adequate. Furthermore, it appears that these three criteria not only have an impact on future computerisation decisions, but they significantly affect long term training and education decisions. The results also show that there is a need for the vendor organisation to consider the major work carried out by the small business when determining the type of support and training to be provided.

This study has presented a number of factors which affect curricula inclusions. Although the results have important implications, additional research is required in a number of areas. Firstly, the reasons why certain measures of satisfaction only appear to affect certain subtopics, depending upon which type of respondent is being examined. In order to pursue this, these t;actors need to be refined and followed up by extensive interviewing. Secondly, a wider study needs to be undertaken to determine if city based and country based small businesses react differently to college course inclusions. Finally, a more intensive examination needs to be carried out to examine how small businesses communicate with vendors, such that the effect of various measures of satisfaction may be better explained.

\section{References}

Ang, A. Y. (1992). Information Systems Curricula: A Southeast Asian Perspective. Journal of Computer Information Systems, 7-15.

Ang, A. Y. \& Lo, B. W. N. (1991). Changing emphasis in information systems curriculum: An Australian Industrial Perception. Proceedings of the Second Conference on Information Systems and Database Special Interest Group, pp. 339-355.

Barnett, R. R. \& Mackness, J. R. (1983). An action research study of small firm management. Journal of Applied Systems, 10, 63-83. 
Brigham, E. F. \& Smith, K. V. (1967). The cost of capital to the small firm. The Engineering Economist, 13(1), 1-26.

Chen, J. C. (1993). The impact of microcomputers on small businesses: England 10 years later. Journal of Small Business Management, 31(3), 96102.

Cochran, A. B. (1981). Small business mortality rates: A review of the literature. Journal of Small Business Management, 19(4), pp. 50-59.

Cragg, P. B. \& King, M. (1993). Small firm computing: Motivators and inhibitors. MIS Quarterly, 17(1), 47-60.

Delone, W. H. (1988). Determinants for success for computer usage in small business. MIS Quarterly, 51-61.

Delvecchio, M. (1994). Retooling the Staff along with the system. Bests Review, 94(11), 82-83.

Holzinger, A. G. \& Hotch, R. (1993). Small firms usage patterns. Nations Business, 81(8), 39-42.

Igbaria, M. (1993). User acceptance of microcomputer technology: An empirical test. International Journal of Management Science, 21, 73-90.

Illawarra Business Directory (1993). W J Public Relations.

Khan, E. H. \& Khan, G. M. (1992). Microcomputers and small businesses in Bahrain. Industrial Management and Data Systems, 92(6), 24-28.

Lo, B. W. N. (1991). Australian information systems curricula. The Journal of Computer Information Systems, 31, 20-33.

MacGregor, R. C. \& Cocks, R. S. (1991). A non-technical methodology for the purchase of software applicable to the veterinary practice. Australian Veterinary Practitioner, 22,104-108.

MacGregor, R. C. \& Cocks, R. S. (1994). Computer usage and satisfaction in the Australian veterinary industry. Australian Veterinary Practitioner, 25(1), 43-48.

MacGregor, R. C. \& Bunker, D. J. (1995). The effect of criteria used in the acquisition of computer technology on the ongoing success with information technology in small business. Forthcoming.

Meredith, G. G. (1994). Small Business Management in Australia. 4th ed. Sydney: McGraw Hill.

Neergaard, P. (1992). Microcomputers in small and medium sized companies: Benefits achieved and problems encountered. Proceedings of the Third Australian Conference on Information Systems, Wollongong, Australia.

Reynolds, W., Savage, W. \& Williams, A. (1994). Your Own Business: A Practical Guide to Success. ITP.

Rotch, W. (1967). Management of Small Enterprises: Cases and Readings. University of Virginia Press. 
Seeborg, I. S. \& Ma, C. (1989). MIS program meets reality: A survey of alumni from an undergraduate program. Interface, 10, 51-60.

Trauth, E. M., Farwell, D. W. \& Lee, D. (1993). The IS expectation gap: Industry expectation versus academic preparation. MIS Quarterly, September, 293-307.

Waldhalm, S. J. (1991). Client databases and written communications. Proceedings of the Eastern States Veterinary Conference, Orlando, pp.637.

Walker, E. W. (1975). Investment and capital structure decision making in small business. In E. W. Walker (Ed.), The Dynamic Small Firm: Selected Readings. Austin Press, Texas.

Wood, J. G. \& Noiek, J. T. (1994). Discrimination of Structure and Technology in a Group Support System: The Role of Process Complexity. ICIS, Vancouver, pp. 187-199.

Yap, C. S., Soh, C. P. P., \& Raman, K. S. (1992). Information systems success factors in small business international. Journal of Management Science, 20, pp. 597-609.

Contributors: R. C. MacGregor, and D. J. Bunker are from the Department of Business Systems, University of Wollongong. R. S. Cocks is at the Wollongong Veterinary Hospital, and J. K. Pierson and K. A. Forcht are with the Department of Information and Decision Sciences, James Madison University. Address for Correspondence: Robert MacGregor, Department of Business Systems, University of Wollongong, Wollongong NSW 2522, Australia.

Please cite as: MacGregor, R. C., Bunker, D. J., Cocks, R. S., Pierson, J. K. and Forcht, K. A. (1995). Do vendor/consultant services affect small business' IT course requirements? Australian Journal of Educational Technology, 11(1), 50-67. http: / / www.ascilite.org.au / ajet / ajet11 / mcgregor.html 